\title{
The Body Suffering and Care Possibilities: A Reflective Look from the Health Economics
}

\author{
José Humberto Cardoso Resende, Allan Peixoto de Assis, \\ Lucilia Feliciano Marques di Carlantônio, Luiz Célio Martins Freitas, Teresa Tonini, \\ Nébia Maria Almeida de Figueiredo, Luiz Carlos Santiago \\ Universidade Federal do Estado do Rio de Janeiro (UNIRIO), Rio de Janeiro, Brazil \\ Email: jresen99@hotmail.com
}

Received 9 December 2015; accepted 22 February 2016; published 25 February 2016

Copyright (C) 2016 by authors and Scientific Research Publishing Inc.

This work is licensed under the Creative Commons Attribution International License (CC BY). http://creativecommons.org/licenses/by/4.0/

c) (i) Open Access

\begin{abstract}
This article aimed to show ideas about the themes: body suffering, nursing and Medical care, and Health Economics. To this end, we tried to put together a kaleidoscope of references that converged on the promotion of autonomy and empowerment and, as a strategy for action, and then we can think of what to do to alleviate the suffering of patients.
\end{abstract}

\section{Keywords}

Health Economics, Nursing, Medicine

\section{Introduction}

The search for more effective and efficient models of providing health care is a permanent and global objective whose importance increases as a function of the characteristic of the phenomenon of demographic transition observed in recent decades, with a notable increase in the elderly population. Among other developments, we see increasing demand for assistance to patients with chronic diseases, one of the most eloquent examples of the biomedical model, once hegemonic, it must at least be repositioned within the logic of care to the body suffering [1]-[3].

Contributing directly to the worsening scenario, is still a growing appreciation of the high technological complexity care at the expense of primary care actions that could drastically reduce not only the need for such care as also compete for better quality levels of living [4].

In short, things that do not end in themselves, but conform an intricate mosaic of interrelations whose understanding and management necessarily call for new looks.

In the wake of this amalgamation, however, there is an even more disturbing element: in many countries, with

How to cite this paper: Resende, J.H.C., de Assis, A.P., di Carlantônio, L.F.M., Freitas, L.C.M., Tonini, T., de Figueiredo, N.M.A. and Santiago, L.C. (2016) The Body Suffering and Care Possibilities: A Reflective Look from the Health Economics. Health, 8, 285-292. http://dx.doi.org/10.4236/health.2016.84030 
different allocation and financing systems, health expenditures tend to grow exponentially, without, however, being observed a proportional increase of care quality. That is to say in the clearest terms that not only spends a lot, but—and especially_-is spent badly [5] [6].

In a recent interview on the subject of health spending scenario in the United States, Betty Rambur stated that, according to the two major centers to provide American medical services, Medicare and Medicaid, $1 \%$ of that country's population consumes about $22 \%$ of the resources allocated for this purpose, of course due to the complexity of their care demands. However, under the gaze of Health Economics, this clearly points to the need for new models that can reconcile the delivery of quality care to an economically sustainable system of funding and allocation of adequate management resources to hospitals. Also in this aspect, it draws attention to the fact that growing evidence suggests that at least one-third of health expenditures do not represent an actual benefit to the assisted population, with some estimates indicating that about half of the nearly missed three trillion allocated dollars. Also, a significant portion of care would result in injuries or even death. Moreover, these astronomical figures reduce the possibility of greater investment in social determinants of health, for example, adequate housing, food security, and education, which could provide a more significant impact on improving the health conditions of the mere extension of the offer of assistance [7].

Academic production within the nursing and medicine is replete with evidence of the search for new looks. Indeed, it may be affirmed without exaggeration that interdisciplinarity is an unequivocal mark of a significant portion of this production. However, when the considered look is an economic one, noticeable drop is seen in this production.

Amid this ambiance, this article is above all an invitation not only to reflect but also to inspired and transformative action.

Permeating the subject matter presented, there is the idea that sustainability will be the great paradigm of the XXI century and facing multiple contexts of scarcity scenarios, the economic sustainability tends to play increasingly important role in decision-making processes.

However, in health care, especially in hospital spaces, crises can present themselves as privileged moments for the inspired and transformative action or, if you prefer it a more technical terminology, for innovation [8].

For example, the oil crisis that marked so damaging effect on oil importing economies throughout the 1980s also allowed leveraging the interest in alternative energy sources and the process, the concept of environmental sustainability, quite innovative at the time was incorporated into the social repertoire, establishing new perceptions of value [9].

There is also a second idea: that, to transform the care in a truly innovative perspective, we must first transform the professionals who care, requiring new forms of care, considering the relief of human suffering. However, it is believed that this will not be triggered by changes in vocational training processes and the regulation of new possibilities for action, although it is plausible that both tend to realign with the new emerging demands, dealing with the environment and poverty.

The authentic transformation is not a vertical process that part of a decision-making summit, but are triggered by the conviction of each that change is not only necessary but also urgent. So the transformation is never sudden, when it seems to be, is only apparent [10] [11].

It is speculated here that as nursing and medicine can contribute to this transformation, which can only occur towards overcoming the invisible care executor of paper, or even managerial mediator, to take on a truly entrepreneurial attitude.

It is a trend already observed in other countries, notably the English language [12]-[14].

Thus, this article aimed to sow ideas on health care, with the guiding principle the perspective of Health Economics and care possible of the body suffering.

In the specific case, the body of women with Gigantomastia covering many issues of interest to nursing and medicine, involving health economics and care costs; of emotions felt by women before, during and after surgery.

\section{Understanding Health Economics Essentials}

\subsection{Background}

The Health Economics, as constituted knowledge, is a fairly recent epistemological construct and whose emergence was restrained, largely because this convergence was seen for a long time, not just as incongruous, but even untenable [15] [16]. 
On the one hand, economists had no greater interest in the health market, since it can not be grasped by the logic of a perfectly competitive market, one of the pillars of the capitalist model in its various guises [15] [16].

In turn, health professionals in general but especially professionals in nursing and medicine, had their targeted training in order to internalize an individualistic ethics, hinged on the assumption that a life is priceless, not an ethic of the common good, which shifts the allocation priority of care resources available to meet the needs of the largest possible number of people, even at the expense of attention to the needs of specific groups [15] [16].

This assumption of incompatibility, however, fell apart in the face of multiple and significant economic impacts of this market. Analyze it. Therefore, it has emerged as an object of interest to economists, justifying the targeting of efforts to establish the differential aspects of this market compared to the perfectly competitive market [15] [16].

From health professionals, however, similar interest was not observed, most of the curricula of undergraduate and even of Nursing graduate and medicine do not provide any opportunity for issues related approach to how resources are allocated to the health sector and/or how these resources are distributed in its scope, key areas of interest Health Economics [15] [16].

\subsection{Health and Market Singularities}

The starting point of any economic analysis is the assumption that a competitive market is the most efficient way to distribute limited resources. The problems of applying this model to healthcare are well recognized, but some authors suggests that by using regulation and alternatives to markets, some of the desirable features of perfectly competitive markets can be replicated. This is a complex issue and is not intended here to offer an extensive analysis of it. Nevertheless singularities directly related to this market will be analyzed with regard to supply and demand behavior.

The characteristics that single out the health care market have attracted the interest of several authors, from the pioneering work of Kenneth Arrow [17].

For the point of view of supply, the intention of profit does not explain by itself, the healthcare market organization and presence in the market of public institutions and different arrangements of private non-profit makes its dynamics more complex.

On the other hand, the demand pressure requires not only constant increase in supply but calls for a more equitable access to services for the entire population.

Thus, the social demand for greater coverage leads the state to create and maintain, directly or indirectly, health services, which does not mean or guarantee proper care of the body suffering, because it spends little with people and material so that it care properly.

Generating distortions that sometimes the spaces may have to take care of advanced technologies and do not offer, for example, an analgesic, because no.

From the point of view of demand, consumers do not opt for the consumption of health services by free and rational choices, compared to other possible options, but do so whether or not the consumption of such services.

This consumption, in general, is unpredictable and does not allow consumers to choose the best moment to do it, based on your personal criteria.

Who, ultimately, will establish what is consumed is not the consumer but an expert.

Since it is unlikely that the consumer holds the same information as the expert who will take the consumer decisions, information asymmetry is presented as a defining characteristic of this market, contrary to what would occur in a competitive market where everyone involved would share the same informational level [18] [19].

Grossman [19] applied the theory of human capital in the health context to explain the demand in this sector. As the health status does not detract instantly, lasting over time, it can be analyzed as a capital asset that will tend to vary over the years, at different rates. Moreover, it could also be analyzed with both a consumer good like a good investment. As a consumer, demand for healthcare is guided by the intention to feel better. While capital assets, guided by efforts to achieve the greatest possible number of healthy days. According to this logic, consumers play an active role in the production of this capital, as they apply health inputs, which may include health care itself, but also, for example, investments in adopting a healthier lifestyle through a more balanced diet and regular physical activity. The demand for health care will be guided by its final product, i.e., healthy days, determining the contribution of time and resources to be committed to achieving this goal. 


\section{Possibilities of Interdisciplinary Care under the Look of Health Economics}

It is always appropriate to recall, as does Merhy ([20], p. 108) that, in the health field, the object is not the cure or the promotion or protection of health, but the production of care, through which both healing and health, can be reached.

In this context, over the centuries, the field of Health has been built as a field of professional technical practices that care, socially determined, under which the medical course of action has become hegemonic. Nevertheless, even considering this particular course of action, there are a variety of models of care, defined as technical (involving all kinds of procedure) and careful expression (involving art, sensibility, emotion, aesthetics, attention Human Body, solidarity that also produce health) care as knowledge production space and do a “ecosophy" (ecological philosophy that involves caring for the environment, with human interactions).

To Cecilio [21], care means providing and availability of health technologies according to the unique needs of each person, at different times of his life, seeking their welfare safety, and autonomy to continue with a productive and happy life.

It is now present the third idea.

It has just been proposed that it is not possible to transform the care of an innovative way if there is no genuine transformation of the professional who cares. However, logics of care is not defined only by these two agents, but also involves the participation of a third party who is responsible for the organization and operation of the system, and that third agent may be the State, engaged in the provision of public services, or, different private or mixed business arrangements. Moreover, in light of the failures of the healthcare market, it is up to the State regulatory role performance. Thus, the role of the state is always relevant to the dynamics of healthcare systems [22].

As it is not intended here to review the features that single out the different health systems now operating in the world, the subsequent argument will be based on the Brazilian health system and. Therefore, it is considered appropriate to assess, albeit briefly, some features the administrative culture of the State in Brazil.

The Brazilian state has emerged in a patrimonial culture, one of the perverse legacies of its socio-historical formation process.

It is a very broad topic and approach it succinctly always involves some risk of misunderstanding both in your statement and in its interpretation.

So, we chose here for the simple assertion of that statement, as well as its most significant impact on the administrative culture of this state: patrimonialism.

Patrimonialism has the characteristic defining the differentiation between public and private is a hallmark of the absolute monarchies.

In the transition to the twentieth century, this differentiation was incompatible with the logic of industrial capitalism, which demanded a clear distinction of roles between the public and private actors.

In Brazil, however, by the strong rootedness of patrimonial culture in the social imaginary, this separation took place under more appearances, contaminating the way the Weberian bureaucratic model was implemented in the Brazilian Public Administration [23].

The accession of Brazil to the bureaucratic model of management defined the scope of its first major administrative reform, through the constitution promulgated in 1937.

According to Costa [23] this bold initiative sought to introduce the administrative apparatus of the country centralization, impersonality, hierarchy, the merit system, the separation between public and private. Its scope, therefore, was to be a more rational and efficient public administration, able to assume its role in driving the development process, a model based on industrialization through import substitution, demanded a strong state intervention and control over relations between the ascending social groups - the new industrial bourgeoisie and urban working class.

Three decades later, a second reform would be conducted in a neoburial model and mediated important decentralization mechanisms.

Its execution, however, was not full.

For many authors, the window of opportunity has been lost to a quality management jump [23] [24].

As part of public opinion, however, the understanding is enshrined, that decentralization was more vulnerable to patrimonial and corrupting practices. The spread of this understanding was not fortuitous nor random, but there is no room to exploit it at the time. 
The 1970s brought the first signs of an international crisis of the state, however, would set up more clearly only during the next decade.

The third reform of the Brazilian state began at that time. However, when the global crisis state emerged more forcefully in the 1990s, Brazil had just enacted the Constitution of 1988, despite its merits, it resulted in a management challenge that still has not been overcome and, from an economic point of view, it is implausible that is, ensuring a wide range of rights to be guaranteed by State [23] [24].

Despite the long delay, the third major administrative reform of the Brazilian state sought It gears him to face this challenge. In this regard, it should be noted, according to Matias Pereira [24], legally inaugurated by Constitutional Amendment No. 19 of June 4, 1998, this initiative intended to strengthen the administrative capacity of the Brazilian state and to foster the autonomy of agencies and social organizations.

Regarding the scope of this article, the Constitution of 1988 radically innovated by introducing the abandonment of a social security health model, which limited the right to health workers with formal integration into the labor market to establish a universal model, the Unified Health System (SUS).

In practical terms, however, the SUS is still far from secure, efficient, effective and effectively, universal coverage of the health needs of the population [25].

Since it does not intend to proceed with this approach this scenario in its determinants and conditioning, it will be seized only as a crisis to be interpreted as innovation opportunity [26].

The elements here appreciated the way those involved in the logics of care production certainly not run out, but allow it to be identified the concept that, according to this article, allows articulate them: the concept of autonomy.

A problem that can immediately be identified is that the use of the term autonomy has become so widespread that this polysemy compromises their understanding in specific contexts. Therefore, it is necessary to present the third idea previously announced in a clearer way.

In a process of intervention, one that will intervene, ideally, should perform four steps: observe, analyze, decide and act.

So when it is employed the term autonomy herein, reference is made to the degree of freedom that this process will take place from the perspective of one who triggered the process, an interdisciplinary methodology that extends challenges, but also many hopes.

The autonomous act, it should be noted, it is not anarchic or random.

Presupposes ability to make decisions and take responsibility for them.

It's a hard issue, where there are few points of consensus and, roughly speaking, this can be evidenced by the steep rise in lawsuits.

Indeed, there is a very interesting aspect in this scenario, and that is directly related to that argument: what is the cost of lack of preparation for autonomy?

This unpreparedness, in turn, demands a state that in a containment effort deleterious effects advances to regulate increasingly a wider range and more intensely aspects before consigned to the personal decision of the ball or groups as a family.

An increasing volume, even something insane, legal devices standing normative published, regulated and often ignored.

Intensify, then, the mechanisms of repression of socially unsustainable behavior. However, rising costs and unimpressive results should awaken society to the fact that it is heading in the wrong direction [27].

What this relates to the provision of care context? Certainly more than it seems at a first examination.

It is not something easy, nor should it be expected consensus.

So, the next topic will present a quite new perspective and here is identified as promising.

It is not, of course, to identify it as a panacea for ills arising from lack of preparation for independence, but to seek to grasp it in its possibilities.

\section{Nursing, Medicine, Autonomy and Entrepreneurship (New Ways to Care for the Body Suffering)}

The word entrepreneur may also be considered polissemic also due to its use in various contexts.

In this sense, it is worth clarifying, is used here in the original meaning of intermediaries, such as this French and English. The entrepreneurial action, in turn, can contemplate various goals. 
From an economic point of view, for example, may or may not have profit as the ultimate goal.

The first possibility defines the so-called business entrepreneurship.

When we walked to the achievement of important social goals, conforms the so-called social entrepreneurship.

The strategies that enhance success in both scenarios, however, are not incompatible, even markedly different and this compatibility, unsuspected an initial review, you should raise awareness among care professionals to adopt a more open attitude and attentive to the economic view and perhaps understand that the hospital or another service is a company that creates and produces services [28]-[30].

Social entrepreneurship expression has been increasingly used to describe the emerging paradigm of promoting development through network systems and partnerships, able to contemplate the human condition in its collective dimension [26] [28].

It has also been recognized as an inducer potential self organization the social system, through promotion strategies of autonomy in multiple vectors, including economic sustainability [28]-[32].

Social entrepreneurship is based on the confrontation of welfare, one of the defining characteristics of the biomedical model that, in turn, contributed directly to the consolidation of social understanding that identifies interchangeably health care provision and care nursing in Cheers [28] [30].

There is no question, of course, health care, or the care of medium and high technological complexity needed.

Instead, it intends to reiterate inconsistent alignment with the humanized care culture, that these responses are not universal and must be confined to the demands peculiar to it.

On the other hand, there are other needs that can not be adequately addressed by this model, to meet the same, social entrepreneurship can present itself as an innovative and emancipatory perspective [31] [32].

Although the available literature on social entrepreneurship in healthcare has been produced in Englishspeaking countries and, therefore, referred the cultural and organizational contexts very specific, evidence of the contribution is interesting and provocative [28]-[32].

In Brazil, qualitative study developed based on Grounded Theory, also pointed in this direction, there is, however, a need for more studies, which should take place due to the interest that this perspective can awaken in the context not only of Brazilian nursing but of all professions that make up the area of health.

\section{Final Considerations}

Throughout this article, we tried to share the perception that there is an imperative and urgent demand for change in health logics of care productionc in general and nursing and medical care in particular.

First, however, by giving complete the task, the Court finds that the body was suffering the text presented here refers.

It is a review of why reference is made to the body and not to the person suffering.

This is due essentially to the fact that the body is the locus of expression of all the suffering that can be experienced by someone, whether it be pain perceived by others as real or imaginary.

The body is the tangible dimension of suffering and their needs can not be fully satisfied only by a medicalized attention, but many other types of attention to taking care to ensure the specificity of each profession.

Also sought to share the perception that the body suffering claims autonomy, empowerment, that is, it tells us that or suggest treatment and care through symptoms, signs that we should follow.

Although this condition is not particularly visible about customers, frankly the significant impact of investments in promoting self-care clearly pointed out that this demand installed, although in varying degrees.

However, it is about the body of the professional who takes care that this suffering is more eloquent, even as it is less visible and valued.

The involvement of health professionals by diseases such as insomnia, chronic pain, and high blood pressure, are evidence of a suffering that has no other form of expression.

Transforming this scenario is imperative and, of course, this will not graciously offer.

In this context, social entrepreneurship may be a promising alternative.

Finally, it should be noted that all human constructions can be distorted in such a way that it is unlikely to rescue the original motivation.

Social entrepreneurship is not exempt from that possibility, but inertia does not offer any benefit.

The nursing care or other professionals such as social practice can be transforming for all those involved in 
the logics of care production, breaking with the welfare culture that perpetuates dependency, submission and therefore suffering.

\section{References}

[1] Bloom, D.E., Canning, D. and Fink, G. (2010) Implications of Population Ageing for Economic Growth. Oxford Review of Economic Policy, 26, 583-612. http://dx.doi.org/10.1093/oxrep/grq038

[2] Mitchell, O.S., Piggott, J., Sherris, M. and Yow, S. (2006) Financial Innovation for an Aging World (No. w12444). National Bureau of Economic Research, Cambridge, MA. http://dx.doi.org/10.2139/ssrn.921041

[3] Lunenfeld, B. and Stratton, P. (2013) The Clinical Consequences of an Ageing World and Preventive Strategies. Best Practice \& Research, 27, 643-659. http://dx.doi.org/10.1016/j.bpobgyn.2013.02.005

[4] Schoen, C., Osborn, R., Huynh, P.T., Doty, M., Zapert, K., Peugh, J. and Davis, K. (2005) Taking the Pulse of Health Care Systems: Experiences of Patients with Health Problems in Six Countries. Health Affairs-Millwood VA Then Bethesda MA, 24, W5. http://dx.doi.org/10.1377/hlthaff.w5.509

[5] Berwick, D.M., Nolan, T.W. and Whittington, J. (2008) The Triple Aim: Care, Health, and Cost. Health Affairs, 27, 759-769. http://dx.doi.org/10.1377/hlthaff.27.3.759

[6] Jönsson, B. (2004) Changing Health Environment: The Challenge to Demonstrate Cost-Effectiveness of New Compounds. Pharmacoeconomics, 22, 5-10. http://dx.doi.org/10.2165/00019053-200422004-00003

[7] Rambur, B. and Nickitas, D.M. (2015) Understanding Health and Payment Reform-Essential for the New World of Nursing: An Interview with Betty Rambur. Nursing Economics, 33, 155-162.

[8] Drucker, P. (2014) Innovation and Entrepreneurship. Routledge, New York.

[9] Koh, L.P. and Ghazoul, J. (2008) Biofuels, Biodiversity, and People: Understanding the Conflicts and Finding Opportunities. Biological Conservation, 141, 2450-2460. http://dx.doi.org/10.1016/j.biocon.2008.08.005

[10] Kotter, J. P. (1995) Leading Change: Why Transformation Efforts Fail. Harvard Business Review, 73, 59-67.

[11] Kotter, J.P. and Cohen, D.S. (2002) The Heart of Change: Real-Life Stories of How People Change Their Organizations. Harvard Business School Press, Boston.

[12] White, K.R. and Begun, J.W. (1998) Nursing Entrepreneurship in an Era of Chaos and Complexity. Nursing Administration Quarterly, 22, 40-47. http://dx.doi.org/10.1097/00006216-199802220-00008

[13] Gibb, A. (2011) Concepts into Practice: Meeting the Challenge of Development of Entrepreneurship Educators around an Innovative Paradigm: The Case of the International Entrepreneurship Educators' Programme (IEEP). International Journal of Entrepreneurial Behavior \& Research, 17, 146-165. http://dx.doi.org/10.1108/13552551111114914

[14] Boore, J. and Porter, S. (2011) Education for Entrepreneurship in Nursing. Nurse Education Today, 31, 184-191. http://dx.doi.org/10.1016/j.nedt.2010.05.016

[15] Hodgson, G.M. (2008) An Institutional and Evolutionary Perspective on Health Economics. Cambridge Journal of Economics, 32, 235-256. http://dx.doi.org/10.1093/cje/bem033

[16] Folland, S., Goodman, A.C. and Stano, M. (2008) A economia da saúde. 5th Edition, Bookman, Porto Alegre.

[17] Arrow, K.J. (1963) Uncertainty and the Welfare Economics of Medical Care. The American Economic Review, 53, 941-973.

[18] Wonderling, D. (2011) Introduction to Health Economics. McGraw-Hill Education (UK), New York.

[19] Grossman, M. (1972) The Demand for Health: A Theoretical and Empirical Investigation. NBER Books, New York.

[20] Merhy, E.E. (2004) O ato de cuidar: A alma dos serviços de saúde. BRASIL. Ministério da Saúde. Secretaria de Gestão do Trabalho e da Educação na Saúde. Departamento de gestão da Educação na Saúde. Revista SUS Brasil: Cadernos de textos. Ministério da Saúde, Brasília, 108-137.

[21] Cecílio, L.C.O. (2011) Apontamentos teórico-conceituais sobreprocessos avaliativos considerando as múltiplas dimensões da gestão do cuidado em saúde. Interface, 15, 589-599. http://dx.doi.org/10.1590/S1414-32832011000200021

[22] Kuhlmann, E. (2006) Modernising Health Care: Reinventing Professions, the State and the Public. Policy Press, London.

[23] Costa, F.L. (2008) Brasil: 200 anos de Estado; 200 anos de administração pública; 200 anos de reformas. RAP—Rio de Janeiro, 42, 829-874. http://dx.doi.org/10.1590/s0034-76122008000500003

[24] Matias Pereira, J. (2010) Curso de administração pública: Foco nas instituições governamentais. 3rd Edition, Atlas, São Paulo.

[25] Paim, J., Travassos, C., Almeida, C., Bahia, L. and Macinko, J. (2011) The Brazilian Health System: History, Advances, and Challenges. The Lancet, 377, 1778-1797. http://dx.doi.org/10.1016/S0140-6736(11)60054-8 
[26] Scott, J. (2012) Social Network Analysis. Sage, New York.

[27] Backes, D.S., Erdmann, A.L. and Büscher, A. (2010) O cuidado de enfermagem como prática empreendedora: Oportunidades e possibilidades. Acta Paulista de Enfermagem, 23, 341-347. http://dx.doi.org/10.1590/S0103-21002010000300005

[28] Estrin, S., Mickiewicz, T. and Stephan, U. (2013) Entrepreneurship, Social Capital, and Institutions: Social and Commercial Entrepreneurship across Nations. Entrepreneurship Theory and Practice, 37, 479-504. http://dx.doi.org/10.1111/etap.12019

[29] Keitsch, M., Sigurjonsson, J., Nilsen, B.F. and Spencer, E. (2013) Sustainable Design and Social Entrepreneurship-A Common Path toward Social Innovation? Journal of US-China Public Administration, 10, 618-629.

[30] Boore, J. and Porter, S. (2011) Education for Entrepreneurship in Nursing. Nurse Education Today, 31, 184-191. http://dx.doi.org/10.1016/j.nedt.2010.05.016

[31] White, K.R. and Begun, J.W. (1998) Nursing Entrepreneurship in an Era of Chaos and Complexity. Nursing Administration Quarterly, 22, 40-47. http://dx.doi.org/10.1097/00006216-199802220-00008

[32] Wilson, A., Whitaker, N. and Whitford, D. (2012) Rising to the Challenge of Health Care Reform with Entrepreneurial and Intrapreneurial Nursing Initiatives. Online Journal of Issues in Nursing, 17, 5. 